STUDI

FRANCESI

\section{Studi Francesi}

Rivista quadrimestrale fondata da Franco Simone

169 (LVII | I) | 2013

LA RÉVOLUTION SUR SCÈNE a cura di Pierre Frantz, Paola Perazzolo, Franco Piva

Voyageuses européennes au XIXe siècle. Identités, genres, codes, sous la direction de Frank Estelmann, Sarga Moussa et Friedrich Wolfzettel

\title{
Florence Fix
}

\section{OpenEdition}

Journals

Édition électronique

URL : http://journals.openedition.org/studifrancesi/3435

DOI : 10.4000/studifrancesi.3435

ISSN : 2421-5856

Éditeur

Rosenberg \& Sellier

Édition imprimée

Date de publication : 1 avril 2013

Pagination : 181-182

ISSN : 0039-2944

Référence électronique

Florence Fix, «Voyageuses européennes au xix siècle. Identités, genres, codes, sous la direction de Frank Estelmann, Sarga Moussa et Friedrich Wolfzettel », Studi Francesi [En ligne], 169 (LVII | I) | 2013, mis en ligne le 30 novembre 2015, consulté le 18 septembre 2020. URL : http://journals.openedition.org/ studifrancesi/3435; DOI : https://doi.org/10.4000/studifrancesi.3435

Ce document a été généré automatiquement le 18 septembre 2020.

\section{$\Theta \Theta \Theta \Theta$}

Studi Francesi è distribuita con Licenza Creative Commons Attribuzione - Non commerciale - Non opere derivate 4.0 Internazionale. 


\title{
Voyageuses européennes au XIX $X^{e}$ siècle. Identités, genres, codes, sous la direction de Frank Estelmann, Sarga Moussa et Friedrich Wolfzettel
}

\author{
Florence Fix
}

\section{RÉFÉRENCE}

AA. VV., Voyageuses européennes au XIX ${ }^{\mathrm{e}}$ siècle. Identités, genres, codes, sous la direction de Frank ESTELMAnN, Sarga MousSA ET Friedrich wolfZETTEL, P. U. Paris-Sorbonne, 2012, «Imago mundi», pp. 320.

1 Publié dans la belle collection «Imago mundi» que les P. U. de Paris-Sorbonne consacrent à la littérature de voyage, le volume collectif Voyageuses européennes au XIXe siècle constitue la publication des actes d'un colloque tenu à l'Université de Lyon en 2007 avec la collaboration de l'Université de Francfort-sur-le-Main. Réunissant seize textes, il propose d'interroger le voyage au féminin, non pas comme objet (descriptions de pays ou de lieux uniquement accessibles aux femmes, le harem par exemple), mais comme émergence d'un sujet (la femme-auteur de récit de voyage), où la prise de conscience d'une identité féminine, voire d'une condition féminine au spectacle de la femme étrangère, côtoie une "prise de conscience d'un pouvoir auctorial». Le voyage au féminin et son récit au XIX ${ }^{\mathrm{e}}$ siècle, en tant que phénomènes modernes, posent la quête du sublime et la sublimation de l'espace de découverte oriental comme une revanche au quotidien européen. Doté d'une double introduction très solide, qui prend soin de ne pas cantonner la démarche au strict domaine des gender studies, le volume se déploie en trois parties: la construction de soi, genre et altérité, formes du voyage et possibles narratifs, tandis qu'un quatrième intitulé, «un autre masculin», ne contient, en guise de conclusion et d'ouverture sans doute, qu'un seul texte. 
2 Roland LE HUENEN, qui étudie dans Parler de soi par ricochet: le voyage au féminin ou l'impossible biographie (George Sand, Flora Tristan, Léonie d'Aunet) (pp. 37-53) plusieurs voyageuses européennes, constate que la particularité du récit de voyage au féminin est l'émergence d'un moi intime, d'un sujet minoré car malheureux, qui tend à faire du recours à l'écriture de voyage une réponse à un problème identitaire. S'il paraît difficile de voir dans cet enjeu du voyage en tant que compensation une dimension spécifiquement féminine (l'auteur parle très justement au début de son propos de Chateaubriand), la question du déplacement géographique impliquant une prise de conscience identitaire comme auteur se trouve très élégamment soulevée: les femmes, comme les hommes, quittent souvent leur patrie en quête de reconnaissance, d'identité - mais les hommes partent en étant déjà romanciers, alors que les femmes étudiées par ce volume deviennent auteurs par le récit de voyage (Flora Tristan) ou y confirment leur autoportrait de femme-écrivain (George Sand). Ce sont d'ailleurs encore George Sand et Flora Tristan dont Christine PLANTÉ convoque le souvenir dans Le féminin à l'épreuve des altérités dans "Pérégrinations d'une paria" de Flora Tristan et "Un Hiver à Majorque" de George Sand (pp. 183-205). Le rapprochement montre d'une façon remarquable les limites de la catégorie du féminin et surtout, en confrontant les discours des deux auteurs envers l'animalité et l'altérité, met à jour l'embarras de Sand devant les différences qui fragilisent son idéologie universaliste.

Dans L'Égypte en groupe, en couple ou en solitaire. Trois modalités du voyage au féminin au XIXe siècle (Suzanne Voilquin, Valérie de Gasparin et Lucie Duff-Gordon) (pp. 241-255), Sarga Moussa évoque la façon dont les voyageuses échappent à l'idéologie orientaliste en s'intéressant au sort des femmes dans les pays qu'elles découvrent. Preuve s'il en était besoin que le volume ne se restreint pas au féminin, le propos de Philippe RÉGNIER (Entre deux mondes, entre deux races, entre deux sexes: la relation égyptienne de Thomas-Ysmaül Urbain, pp. 275-296) offre une lecture du parcours du poète entre l'Égypte et la France comme choix d'une identité de compromis.

4 Le volume réjouira les lecteurs de Flora Tristan notamment, mais plus largement présente le grand intérêt d'interroger la construction d'une identité par le voyage, identité féminine et identité auctoriale, à une époque où l'une comme l'autre de ces activités sont majoritairement masculines. 